\title{
Trivium
}

Revue franco-allemande de sciences humaines et sociales - Deutsch-französische Zeitschrift für Geistesund Sozialwissenschaften

$31 \mid 2020$

La culture politique de la République romaine

\section{Die Regeln der Gewalt in den Volksversammlungen der Römischen Republik}

Jean-Michel David

Traducteur : Andreas Wittenburg

\section{CpenEdition}

Journals

Édition électronique

URL : https://journals.openedition.org/trivium/7188

DOI : $10.4000 /$ trivium. 7188

ISBN : 1963-1820

ISSN : 1963-1820

Éditeur

Les éditions de la Maison des sciences de l'Homme

\section{Référence électronique}

Jean-Michel David, „Die Regeln der Gewalt in den Volksversammlungen der Römischen Republik“

Trivium [Online], 31 | 2020, online erschienen am 30 Juni 2020, abgerufen am 24 August 2021. URL:

http://journals.openedition.org/trivium/7188 ; DOI: https://doi.org/10.4000/trivium.7188

Ce document a été généré automatiquement le 24 août 2021.

\section{(c) $(1)$}

Les contenus des la revue Trivium sont mis à disposition selon les termes de la Licence Creative Commons Attribution - Pas d'Utilisation Commerciale - Pas de Modification 4.0 International. 


\title{
Die Regeln der Gewalt in den Volksversammlungen der Römischen Republik
}

\author{
Jean-Michel David \\ Traduction : Andreas Wittenburg
}

\section{NOTE DE L'ÉDITEUR}

\section{Originalausgabe | édition originale}

"Les règles de la violence dans les assemblées populaires de la République romaine«, Politica Antica, 3, 2013, S. 11-29.

Wir danken Herrn Jean-Michel David und der Zeitschrift Politica Antica für die freundliche Genehmigung, diesen Artikel in deutscher Übersetzung zu publizieren. Nous remercions M. Jean-Michel David et la revue Politica Antica de nous avoir accordé l'autorisation de traduire ce texte pour le présent numéro.

\section{Vorbemerkung}

1 In dem hier folgenden Aufsatz geht es um die Untersuchung eines Musters kollektiven Verhaltens, das in der politischen Kultur der Römischen Republik eine wichtige Rolle spielte. Wenn man die Mechanismen betrachtet, die in den Versammlungen des Volkes, seien es contiones oder auch Komitien, Gewalt erzeugen konnten, so wird man feststellen, dass sie nichts von Spontaneität an sich hatten. Cicero hat das in der im Jahre 56 v. Chr. vorgetragenen Rede zur Verteidigung des Sestius in dem gegen diesen angestrengten Prozess deutlich gesagt. Alle Berichte von Episoden, in denen plötzlich Gewalt zwischen den Bürgern aufkam, beschrieben dieselbe Folge der Ereignisse: der Streit begann zwischen den Magistraten, griff dann auf die Zuhörerschaft über und wurde erst durch den Sieg einer der beiden Parteien gelöst oder durch die 
Unterbrechung, die das Einbrechen der Dunkelheit erzwang. Dieses Schema wird ebenso bei den Annalisten eingehalten, die die Ereignisse der Vergangenheit rekonstruierten, wie von den Akteuren, die sich auf die Auseinandersetzungen vorbereiteten oder die, wie Cicero, das von ihnen erlebte Geschehen schilderten. Das Interesse dieser Betrachtung liegt darin, dass sie einerseits erlaubt, die Genauigkeit der kollektiven Verhaltensmodelle im Funktionieren der römischen Institutionen $\mathrm{zu}$ unterstreichen oder, mit anderen Worten, die politische Kultur, selbst in Situationen, wo die Spontaneität sich scheinbar hätte durchsetzen müssen, und andrerseits zeigt, dass die Verantwortung des Handelns selbst in den Fällen, in denen das Volk in Wahrheit ein entscheidender Akteur war, bei den Magistraten lag. Diese Beobachtungen haben so $\mathrm{zu}$ den Überlegungen beigetragen, die man über den vorhandenen oder fehlenden demokratischen Charakter im Ablauf der Beziehungen zwischen den römischen Bürgern und ihrer Aristokratie anstellen kann. Sie unterstützen ganz offensichtlich die Vorstellung, dass die Realität der Verhaltensweisen weit über die Schilderungen des Polybios hinausging und die einer Aristokratie war, die alle Entscheidungen selbst traf und kontrollierte.

$\star$

2 Im Jahre 56 v. Chr. kam Cicero in der Gerichtsrede, die er zur Verteidigung des de vi angeklagten P. Sestius vortrug, auf die Ereignisse des vorangehenden Jahres zurück und insbesondere auf die Gewalttätigkeiten, die den Volkstribunen Q. Fabricius daran gehindert hatten, dem Volk das Gesetz vorzulegen, das ihm seine Rückkehr aus dem Exil erlauben sollte. Bei Gelegenheit der Beschreibung dieser Episode, deren besonders dramatische Intensität er hervorhebt und für die er kaum vorangehende Beispiele sieht, vergleicht er deren Verlauf mit den Konflikten, die sich üblicherweise in den Volksversammlungen ereigneten und die auf Situationen der Spannung oder sogar auf brutale Handlungen hinauslaufen konnten:

»Nam ex pertinacia aut constantia intercessoris oritur saepe seditio, culpa atque improbitate latoris commodo aliquo proposito imperitis aut largitione, oritur ex concertatione magistratuum, oritur sensim ex clamore primum, deinde aliqua discussione contionis, vix sero et raro ad manus pervenitur [...]. ॥ $^{1}$

Mit dieser Bemerkung, die er beiläufig machte, definierte Cicero in gewisser Weise die Regeln, die für den Ausbruch der Gewalt in den Volksversammlungen galten. Sie war ohne Zweifel nicht annehmbar, aber da das Übel unvermeidlich war, waren das nach seiner Beobachtung die üblichen Kennzeichen. Die Beschreibung, die er gibt, ist durchaus nicht ohne Interesse. Sie gibt einen fast mechanischen Ablauf der Ereignisse zu verstehen, die er als eine Art zwanghafter Abfolge darstellt und die gewissermaßen als kollektives Paradigma der Verhaltensweise gelten kann.

3 Es war ein Konflikt zwischen den Magistraten, der die Gewalt nach sich zog. Sie verbreitete sich unter der Menge der Bürger durch das Geschrei und die Meinungsäußerungen der Anhänger der einen oder anderen Seite. Wenn die Spannungen anhielten oder weiter wuchsen, spaltete sich die Zuhörerschaft, die normalerweise im Zuhören vereint war, in feindliche Gruppen auf, die sich gegenüberstanden und möglicherweise gewalttätig aneinander gerieten. Diese kurze Schilderung einer erwarteten Gewalt lässt dabei eine bestimmte Anzahl von Regeln erkennen. Der Streit entstand nicht in der Zuhörerschaft, sondern auf der Tribüne. Sein erster Ursprung lag in den Meinungsverschiedenheiten der Magistrate und nicht in der 
Feindseligkeit des Publikums ihnen gegenüber. Die Führer, die sich in Feindschaft gegenüberstanden, wurden von den Anhängern unterstützt, die sie im Volk fanden oder deren Zustimmung sie bereits gewonnen hatten. Doch diese erregten sich nicht aus eigenem Antrieb. Cicero spricht die ganze Verantwortung für die Gewalt den Magistraten und vor allem den populares zu, die die Urheber demagogischer Vorschläge wären. Sie wären es, die durch ihre Meinungsverschiedenheiten die Gewalt entfesselten, und es wäre ihre Verantwortung, sie zu vermeiden oder zu beenden. ${ }^{2}$ Mit anderen Worten war es so, dass die Gewalt in den Versammlungen sich nur entwickelte, wenn die Mitglieder der Aristokratie es wollten. Das läuft daraus hinaus festzustellen, dass die Gewalt in gewisser Weise auch ein mehr oder weniger normal gewordenes Instrument des Regierens darstellte.

Die Darstellung Ciceros wird uns nicht überraschen, denn sie entspricht ganz und gar dem, was wir über das Gewicht der Magistrate im Zusammenspiel der Institutionen der Römischen Republik wissen. ${ }^{3}$ Sie erlaubt dennoch, es ein wenig konkreter zu verstehen. Doch muss man dann noch überprüfen, in welchem Maße sie der Realität der Tatsachen entspricht.

Die Episoden der Gewalt, die die politischen Versammlungen betrafen, sind ziemlich zahlreich. ${ }^{4}$ Das bestätigt, dass die Konfrontation eine erwartete oder zumindest nicht unerwartete Dimension des Ablaufs des institutionellen Lebens waren. Es gab in dieser Hinsicht also keinen Unterschied zwischen den contiones und den Komitien. Cicero traf keine Unterscheidung in diesem Sinne, als er in dem zitierten Text die übliche Gewalt schilderte. ${ }^{5}$ Ohne Frage waren die Probleme im Falle der Komitien schwerwiegender, weil dort Entscheidungen gefällt werden mussten. Die Spannung musste da also stärker sein, und auch der Zwang, dem Gegner nachzugeben. Aber alle Arten von Versammlungen waren doch betroffen.

6 Die Schwierigkeit der Untersuchung liegt vor allem darin, dass die Quellen, die die Auseinandersetzungen beschreiben, weit entfernt davon waren, das auf neutrale Weise zu tun. Sie waren auch nicht zeitgleich mit den Ereignissen und schritten meist zu Rekonstruktionen. Trotz allem bleiben die von ihnen entwickelten Berichte erhellend. Sie folgten nämlich dem logischen Ablauf, den ihr Publikum erwartete, und entsprachen dem Schema, das sich ihm aufdrängte. Das trifft besonders auf die annalistischen Rekonstruktionen $\mathrm{zu}$, die die ältesten Vorkommnisse in ihren Einzelheiten nachvollzogen.

7 Um diesem Stand der Dinge Rechnung zu tragen, wollen wir mit den einfachsten Episoden beginnen, also denen, für die uns die Quellen eine möglichst weitgehend zeitgenössische und spontane Schilderung liefern. Dann werden wir uns den Rekonstruktionen von Szenen der Gewalt zuwenden, zu denen die Annalisten schritten und die man bei Livius und Dionys von Halikarnass findet. In beiden Fällen kann man die Normen ohne zu große Schwierigkeiten ablesen.

8 Dieser erste Ansatz reicht jedoch nicht aus. Am Ende der Republik nahm die politische Gewalt außerordentliche Ausmaße an und artete in wiederholte und besonders dramatische Episoden aus, wie gerade die von Cicero angeprangerte. Die politischen Zusammenkünfte waren offenbar nicht die einzigen Orte, wo die Gewalt zum Ausdruck kam. Die Umzüge, die Treffen auf den Plätzen und in den Straßen lieferten weitere Gelegenheiten. ${ }^{6}$ Diese Konfrontationen waren beabsichtigt und vorbereitet. Aber hielten sie sich im Falle der Versammlungen in diesen Fällen an das Paradigma, das sich etabliert hatte, oder überschritten sie es? Die Frage ist von Bedeutung, weil sie die 
Gültigkeit der kollektiven Verhaltensmaßregeln betrifft, die uns beschäftigen. Sie war ausgeprägt, wenn die Akteure dieser Konflikte unter Beachtung ihrer Logik handelten, oder auch nicht, wenn sie ihr zuwiderhandelten. Wie werden also diese Episoden in einem dritten Abschnitt untersuchen.

9 Die contio von 111 v. Chr., in deren Verlauf Jugurtha daran gehindert wurde, sich zu äußern, liefert ein erstes Beispiel für den Ablauf und die Aufeinanderfolge, die Cicero beschrieb. Der Tribun C. Memmius hatte den numidischen König gezwungen, nach Rom zu kommen, und er hatte das Volk zusammengerufen, um ihm die Enthüllungen zu Ohren zu bringen, zu denen der Numider gebracht werden sollte. Nun hatte Jugurtha aber einen anderen Tribunen bestochen, C. Baebius, der sich dieser Prozedur widersetzte und ihm seinerseits den Dienst erwies, ihn zum Schweigen zu zwingen. Das Volk, das dem König bereits vorher sehr feindlich gesinnt war, entrüstete sich. ${ }^{7}$ Innerhalb der Zuhörerschaft bestand in diesem Fall zwar kein Konflikt, aber man versteht doch sehr wohl, wie die gegenseitige Behinderung der Tribunen, wenn man Sallust Glauben schenken will, die Frustration und Gewalt unter den Bürgern nach sich zog, die sich jedoch nach der Aufgabe der Prozedur und der Auflösung der Versammlung nicht weiter fortsetzten.

Dieses ziemlich einfache Schema eines Widerstreits unter Magistraten, der die Erregung und den Zorn des Volkes hervorrief, ohne es indes zugleich dazu zu verleiten, sich zu spalten und zu Akten der Gewalt hinreißen zu lassen, findet man auch in drei berühmten Konflikten am Ende der Römischen Republik wieder.

11 Der erste findet sich im Bericht, den Cassius Dio, der ohne Frage den von Cicero gegebenen Informationen folgt, von den Gewalttätigkeiten gab, die im Jahre $67 \mathrm{v}$. Chr. die Abstimmung über die lex Gabinia begleiteten. Die führenden Senatoren waren gegen dieses Gesetz, das Pompeius außerordentliche Vollmachten im Kampf gegen die Piraten übertrug, und hatten zwei Volkstribunen, L. Trebellius und L. Roscius, zur Opposition veranlasst. Gabinius brachte den ersten dazu nachzugeben, indem er eine Abstimmung über seine Absetzung vorschlug. Der zweite wagte noch nicht einmal mehr, das Wort zu ergreifen. Die Geste, die er unternahm, um vorzuschlagen, dieses Kommando eher zwei Männern anzuvertrauen als dem Pompeius allein, rief beim Volk ein derartiges Geschrei hervor, dass er still blieb. ${ }^{8}$

Der zweite Konflikt ist der berühmte Widerstand des Tribunen M. Octavius im Jahre 133 v. Chr. gegen das von Ti. Sempronius Gracchus vorgeschlagene Agrargesetz. Die Ereignisse sind uns allerdings nur von späten Autoren beschrieben worden, nämlich Plutarch und Appian, deren Erzählungen einige Schönfärbereien enthalten könnten. Aber wenn man sich auf den Kern der Episode beschränkt, wenigstens so wie Appian sie erzählt, ${ }^{9}$ findet man dasselbe Schema wieder, das Cicero aufgezeigt hat. Im Laufe einer ersten Versammlung verbot M. Octavius dem Schreiber, die rogatio vorzulesen. Tiberius Gracchus überhäufte ihn mit Vorwürfen, aber verschob die Versammlung auf einen anderen Sitzungstag. Als Octavius zu diesem Zeitpunkt auf seinem Widerstand bestand, gerieten die zwei Tribunen in Konflikt; das rief den Aufruhr des Volkes hervor, das sich bereits stark engagiert hatte. ${ }^{10}$ Angesichts des drohenden Aufruhrs überzeugten die "Mächtigen", die dem Schauspiel beiwohnten, die Tribunen, die Angelegenheit an den Senat zu verweisen. ${ }^{11}$

Die Gewalttätigkeiten, die eine Episode des Volkstribunats des C.Cornelius im Jahre $67 \mathrm{v}$. Chr. begleiteten, folgten einem vergleichbaren Schema, das jedoch ein wenig komplizierter ist. Asconius, der die Gerichtsrede kommentierte, die Cicero im Jahre 65 
vortrug, um Cornelius gegen die in diesem Zusammenhang gegen ihn erhobene Anklage de maiestate zu verteidigen, ist ein zuverlässiger Zeuge. ${ }^{12}$ Cornelius brachte ein Plebiszit ein, das zum Ziel hatte, dem Volk die Macht zurückzugeben, eine Person von gesetzlichen Regeln freizustellen. Das stieß auf den Widerstand wichtiger Senatoren, die die intercessio eines anderen Volkstribunen, des P. Servilius Globulus, erreichten. Dieser verbot zum gekommenen Zeitpunkt dem praeco, den Text der rogatio vorzulesen. Cornelius trug dem keine Rechnung, bemächtigte sich des Textes und ging daran, ihn selbst vorzulesen. Der Konsul Piso entrüstete sich, aber er wurde vom Geschrei der Zuhörerschaft übertönt. Er wollte die, die ihn schmähten, von einem seiner Liktoren ergreifen lassen. Der wurde zurückgeschlagen, die Fasces wurden zerbrochen, aus den hinteren Reihen der contio wurden sogar Steine auf den Konsul geworfen. Cornelius hatte dann keine andere Möglichkeit mehr, als die Versammlung aufzulösen und die Angelegenheit vor den Senat zu bringen. Diese Episode folgt demselben allgemeinen Schema wie die vorhergehende. Die Blockierung zog Frustration und Gewalt bei den Anhängern des Vorhabens des Tribunen nach sich. Die Reaktion des Konsuls findet offenbar keinerlei Anhängerschaft. Der Versuch, seine Widersacher festnehmen zu lassen, hat zur Wirkung, die Gewalt in die Versammlung selbst zu tragen und eine Eskalation hervorzurufen, der er fast selbst zum Opfer gefallen wäre. ${ }^{13}$ Alles beruhigte sich jedoch, sobald das Volk nach Hause geschickt worden war.

Die vier Vorkommnisse, die wir erwähnt haben, bieten recht einfache Züge und entsprechen einigermaßen der Definition Ciceros, bis darauf, dass die Aufregung des Volkes im Allgemeinen nur zu begrenzten Überschreitungen führte. Die Zuhörerschaft spaltete sich nicht auf und wurde nicht untereinander gewalttätig. Es gibt aber auch andere Beispiele, wo die Gewalt die Versammlung in einem Ausmaß ergriff, dass es zu Schlägereien kam.

Das war besonders der Fall bei der Meuterei, die im Jahre 212 v. Chr. den Prozess des Publikanen Postumius aus Pyrgi begleitete und die Livius beschreibt. ${ }^{14}$ Der Betreffende hatte sich des Verbrechens des Betrugs zum Nachteil des römischen Staats schuldig gemacht. Die Volkstribunen Sp. und L. Carvilius verfolgten ihn in einem Prozess vor den Komitien und hatten die Versammlung, die über seine Verurteilung zu entscheiden hatte, auf das Kapitol einberufen. Der Angeklagte, der sich der Solidarität der Publikanen erfreute, hatte die Unterstützung eines Volkstribunen gewonnen, der mit ihm verwandt war, des C. Servilius Casca. Ohne Frage war vorgesehen, dass dieser auf die intercessio zurückgriff. Aber im Moment, als er zur Tat schreiten wollte, zögerte der Mann..$^{15}$ Die Versammlung war jedenfalls durch sein Zögern aufgehalten, und diese Unsicherheit spaltete die Menge in zwei Lager: auf der einen Seite waren da die einfachen Bürger, und auf der anderen die Publikanen, die einen der ihren verteidigen wollten. Letztere bildeten eine Bande und besetzten mit Gewalt die ersten Ränge der Versammlung, ohne Zweifel in der Absicht, die Abstimmung zu verhindern. Der Konflikt war eröffnet und auf Anweisung der Konsuln entließen die Tribunen die Versammlung. Die Angelegenheit wurde dann dem Senat vorgelegt, und die Gewalttätigkeiten entwickelten sich nicht von Neuem.

Man kann diese Affäre des Postumius von Pyrgi mit den Zwischenfällen vergleichen, die im Jahre $90 \mathrm{v}$. Chr. die Abstimmung über die lex Varia begleiteten. In dem kurzen Bericht, den Appian davon gibt, erzählt er, dass die römischen Ritter sich in Reaktion auf das Eingreifen der Gegner des Varius zusammengeschlossen hätten, ihnen mit Gewalt entgegengetreten seien und die Beschließung des Gesetzes erzwungen hätten. ${ }^{16}$ 
Vielleicht übertreibt dieser Text die Reaktion der Ritter, aber er hat sie mit Sicherheit nicht erfunden. Wie im vorangehenden Fall ging die Gewalt hier von Individuen aus, die bereits eine Solidargruppe bildeten, sich gegenseitig kannten und sich leicht organisieren konnten.

Man findet eine vergleichbare Situation in den Gewalttaten, die, immer nach einem Bericht des Appian, im Jahre 100 v. Chr. die Abstimmung über das Agrargesetz des Appuleius Saturninus begleiteten. ${ }^{17}$ Die Tribunen, die sich dem Vorhaben widersetzten und von ihm misshandelt wurden, sprangen von der Tribüne herab. Sie wurden von den Bürgern der Stadt Rom unterstützt, die dem Gesetz feindlich gegenüberstanden und vorgaben, dass ein Donnerschlag die Abstimmung verbot. Sie gerieten mit den Bürgern vom Lande aneinander, die für den Vorschlag waren und die Appuleius zusammengetrommelt hatte. Bei den Schlägereien, die sich nun entfesselten, behielten Letztere die Oberhand und das Gesetz wurde beschlossen. Bei dieser Episode folgte die Entwicklung der Gewalt dem von Cicero aufgestellten Schema. Sie ging von der Tribüne aus, um sich dann im Volk auszubreiten. Aber die Auseinandersetzung dieser zwei sich gegenüberstehenden Parteien hatte nichts Spontanes. Sie waren durch vorangegangene Bemühungen der Mobilisierung vorbereitet worden, die die Anhänger und Gegner des Gesetzes angestrengt hatten. ${ }^{18}$ Vielleicht war diese Unterscheidung zwischen Bürgern aus der Stadt und Bürgern vom Lande, die allein bei Appian vorkommt, ${ }^{19}$ auch nur das Produkt einer ihm vorangehenden Überlieferung der Geschichtsschreibung, die die Gegensätze erklären wollte. Doch in jedem Falle, ob sie nun der Realität der Ereignisse entspricht oder teilweise rekonstruiert ist, die Abfolge des Handelns folgte im Wesentlichen dem Paradigma, das Gegenstand unserer Untersuchung ist, außer dass die Magistrate hier eine unmittelbare Rolle in der Austragung der Auseinandersetzungen spielten.

Dieser letzte Punkt ist noch deutlicher in der Erzählung, die der Autor der Rhetorik an Herennius $^{20}$ von den Gewalttätigkeiten gab, die im Jahre $100 \mathrm{v}$. Chr. die Abstimmung über das Getreidegesetz desselben Appuleius Saturninus begleitet hätten. Der Senat hatte angekündigt, dass dieser Vorschlag den Interessen des Staates entgegenstehe. Da Saturninus dem nicht Rechnung trug, auch der Interzession seiner Kollegen nicht nachgab und das Abstimmungsverfahren einleitete, stellte sich der Quaestor Servilius Caepio an die Spitze einer Bande von Gegnern des Gesetzes (cum viris bonis impetum facit), behinderte den Übergang über die Brücken und stürzte die Urnen um.

Der Verlauf der Ereignisse in all diesen Affären bestätigt den ersten von Cicero erklärten Punkt: es war die Blockade, die Gewalt nach sich zog. Sie begann auf der Tribüne und verbreitete sich unter dem Volk. Das war entweder einer Meinung und unterstützte einen der Protagonisten, oder es spaltete sich und die verschiedenen Parteien gerieten aneinander. Aber diese Beispiele machen auch eine andere Dimension deutlich: die Reaktion gewann an Kraft und Wirksamkeit, sobald ein Teil des Publikums bereits mobilisiert war und bereit war einzugreifen. Es konnte sich vor allem um Mitglieder der Aristokratie, Publikanen und Ritter handeln, die über eine gesicherte Solidarität verfügten und bereits organisierte Gruppen bildeten; aber das letzte Beispiel zeigt, dass die Magistrate ihre Anhänger aufstacheln oder sogar selbst zum Konflikt führen konnten. ${ }^{21}$

20 Eine zweite Reihe von Beispielen hat die Gültigkeit dieses kollektive Verhaltensmodels bestätigt. Es handelt sich um all die Konflikte, die die Historiker der augusteischen Zeit, Livius und Dionys von Halikarnass, rekonstruiert haben, wenn sie die Konflikte der 
ältesten Zeit schildern wollten. Die Annalisten, die vor ihnen schrieben, lieferten ihnen nämlich nur flüchtige Erwähnungen oder andere Rekonstruktionen, die ebenso erfindungsreich waren wie alle anderen, die sie verfassten. Aber wenn sie erfunden waren, hieß das noch nicht, dass sie reine Phantasie waren. Die Beschreibungen dieser fiktiven Ereignisse mussten sich notwendigerweise an einem realistischen Schema ausrichten, das ihnen ihre Glaubhaftigkeit verschaffte. Mit anderen Worten folgten die Auseinandersetzungen, die die Annalisten beschrieben, dem Ablauf, den sie und ihre Leser für wahrscheinlich ansahen, $d . h$. dem, den sie gewissermaßen für eine Norm hielten.

21 Wir wollen ein erstes Beispiel bei Dionys von Halikarnass aufgreifen. ${ }^{22}$ Es handelt sich um eine Episode, die dazu bestimmt war, den Respekt zu erklären, dem die Tribunen Anerkennung verschafften und der ihr Recht betraf, sich an das Volk zu wenden ohne unterbrochen zu werden. Im Jahre $492 \mathrm{v}$. Chr. beriefen die Konsuln im Zusammenhang mit dem Konflikt zwischen Patriziern und Plebejern eine Versammlung ein. Dort stritten sie mit den Volkstribunen, wobei die beiden Gruppen sich gegenseitig das Wort abschnitten. Das Klima der Gewalt, das auf diese Weise entstand und das in der herannahenden Nacht schärfer wurde, verbreitete sich unter dem Publikum. Die Plebejer unterstützten die Tribunen und die Patrizier die Konsuln. Die Auseinandersetzung nahm derartige Ausmaße an, dass es die Mobilisierung der Bürger provozierte, die zum Forum strömten. Die Auseinandersetzung drohte in einen Kampf auszuarten, als der plebejische Aedil L. Iunius Brutus das Wort ergriff, von neuem die Oberhand in der Debatte gewann und die Menge beruhigte. Am nächsten Tag stimmte das Volk für ein Gesetz, das seine Forderungen befriedigte.

Das Gesamtschema, das den Ablauf der Ereignisse beherrschte, folgte also dem von Cicero beschriebenen: die Gewalt entstand bei der Auseinandersetzung, die die Magistrate untereinander austrugen, und verbreitete sich im Volk, bis die Versammlung ein Ende nahm. Das bedeutet, dass es sich um das allgemeine Verhaltensmodel handelte, auf das man zurückgreifen konnte, wenn die Rekonstruktion einer Szene kollektiver Gewalt anstand, die eine Volksversammlung betraf. Es entsprach indes nur einem ersten Niveau der Komplexität, wo der Konflikt auf verhältnismäßig spontane Weise entstand und sich im Publikum nur durch die Spaltung in anonyme Gruppen manifestierte.

Bei anderen Episoden sahen die Akteure jedoch die Gewalttätigkeit voraus und bereiteten sich in einer Weise vor, dass mehr oder minder identifizierbare Beteiligte auftraten, die die Initiative ergriffen und ihrerseits in Aktion traten. Das war vergleichbar mit dem, was man in jenen zeitgenössischen Episoden am Ende der Republik festgestellt hat, wo Gruppen oder Einzelne der Gewalt Vorschub leisteten und sie in die Tat umsetzten. Die Art, in der diese Stufen in den Berichten erscheinen, ist auch ein Beleg für die Vorstellung, die die Historiker der Antike sich von dieser vorangehenden Organisation und dieser Fähigkeit zur Initiative machten.

Die Rekonstruktion, die Livius und Dionys von Halikarnass ${ }^{23}$ von den Gewalttätigkeiten geben, die im Jahre $471 \mathrm{v}$. Chr. die Abstimmung über das Gesetz des Publilius Volero zur Übertragung der Wahl der Volkstribunen an die Tributkomitien begleiteten, liefert ein gutes Beispiel. Der Konflikt war latent vorhanden, denn schon das vorangehende Jahr war von Diskussionen gekennzeichnet gewesen und nach Darstellung des Dionys von einem ersten Versuch, über das Gesetz abstimmen zu lassen, den aber die Obstruktion der Patrizier zum Scheitern gebracht hatte. Um ihre Position zu sichern, besetzten die 
Parteien im Vorhinein den Platz, auf dem die Komitien sich versammeln sollten. ${ }^{24} \mathrm{Als}$ der Zeitpunkt gekommen war, begann der Konflikt zwischen den Konsuln und den Tribunen zunächst mit den Rededuellen. Er bekam dann eine ganz andere Intensität, als die Tribunen den Patriziern befahlen, die Versammlung des Volkes zu verlassen. Der Konsul Appius Claudius lehnte das ab, und man wurde Zeuge einer Konfrontation zwischen den viatores der Tribunen und den Liktoren des Konsuls, die in einer treffenden symbolischen Inszenierung den Gegensatz zwischen den beiden Staatsorganen, ihre Ebenbürtigkeit der Macht und ihren unversöhnlichen Charakter zur Schau trugen. Die Gewalt breitete sich natürlich auch in der Versammlung aus. ${ }^{25}$ Die Plebejer standen den Patriziern drohend gegenüber, während Letztere sich weigerten abzuziehen. Die Parteigänger der Tribunen liefen aus der ganzen Stadt herbei. Auf die Schreie folgte das Werfen von Steinen. Und es brauchte alle Kraft und Diplomatie des anderen Konsuls, um die Auflösung der Versammlung und das Ende der Schlägerei zu erreichen.

In dieser Episode war die Konfrontation von vornherein geplant, gewollt und vorbereitet. Die gegnerischen Gruppen hatten sich also schon im Voraus gebildet. Das war auch der Fall in jenem Konflikt, den Dionys von Halikarnass rekonstruiert und der im Jahre $455 \mathrm{v}$. Chr. die Volkstribunen und die Konsuln bei der Abstimmung eines Agrargesetzes in Gegensatz zueinander brachte. ${ }^{26}$ Die gegensätzlichen Gruppen hatten bereits in vorangehenden Versammlungen Gelegenheit gehabt, sich zu formieren. Die Konsuln und die Patrizier hatten sich also vorbereitet und hatten die Rostra und das comitium im Voraus umzäunt und das Forum besetzt. Die Unruhen begannen bei der Eröffnung der Versammlung und setzten sich den ganzen Tag in Rededuellen zwischen Konsuln und Tribunen als Anhängern und Gegnern des Gesetzes fort, unter dem Geschrei der einen oder der anderen. Als man endlich zur Abstimmung schritt, hinderten die Patrizier die Plebejer daran, sich nach Tribus zu gruppieren und untersagten die Annahme des Gesetzes. Dionys nannte an dieser Stelle die patrizischen Familien, die seiner Auffassung nach für diese Situation verantwortlich waren, nämlich die Postumii, die Sempronii und die Cloelii. Es ist hier nicht von Bedeutung, ob das gesichert ist. Die Umstände bei der Durchführung der Behinderungen machte es wahrscheinlich, dass man sie identifizieren konnte. Die Gewalt hatte nichts von Spontaneität. Die Handelnden waren darauf vorbereitet. Es ist umso bemerkenswerter, dass die Ereignisse sich in der Erzählung nach demselben Verhaltensmodell aneinanderreihten, das sich den Berichterstattern offenbar systematisch aufgedrängt hat.

Man muss indes einer geringfügig anderen situation einen besonderen Platz einräumen, nämlich der, wo der Konflikt, der zur Gewalt führte, einen Magistraten in Gegensatz zu Einzelpersonen setzte, die er denunzierte oder anklagte und damit in die Situation brachte, zu reagieren und Unterstützung zu suchen. Wir wollen nicht zu viele weitere Beispiele betrachten. ${ }^{27}$ Zwei Fälle genügen, um die Abläufe des Geschehens deutlich zu machen.

27 Das erste Beispiel könnte der Konflikt sein, in dem nach Livius ${ }^{28}$ im Jahre 325 v. Chr. der magister equitum Q. Fabius Maximus dem Diktator L. Papirius Cursor gegenüberstand, dem er den Gehorsam verweigert hatte. Der Diktator richtete, sobald die Versammlung des Heeres einmal zusammengetreten war, lebhafte Vorwürfe an Fabius und gab dem Liktor den Befehl, ihn zu verhaften und hinzurichten. Fabius, der sich zuvor die Anhängerschaft der Truppe gesichert hatte, appellierte an seine Männer und flüchtete 
sich in den hinteren Teil der Versammlung in die Mitte der ältesten Soldaten. Das Geschrei ergriff nun die ganze Truppe, und die Soldaten, die am nächsten zum Gericht standen, äußerten sich in gemäßigterem Ton, während die weiter entfernten im Schutz der Anonymität in Schmähungen ausbrachen. ${ }^{29}$ Die Gewalt entwickelte sich nicht noch weiter, aber sie nahm doch erst mit Einbruch der Nacht ein Ende, der die Auflösung der Versammlung erzwang. Fabius nutzte diesen Vorteil, um in Rom Zuflucht zu suchen. Das Verfahren wurde fortgesetzt, aber durch Reden und ein Ersuchen um Begnadigung geschlichtet.

Man könnte diese Episode mit den Erzählungen der Zwischenfälle vergleichen, die dem Prozess des Coriolan vor den Komitien im Jahre 491 v. Chr. vorangingen. Die wichtigste Rekonstruktion, die uns erhalten ist, ist die des Dionys von Halikarnass, der sich zwei aufeinanderfolgende Phasen der Ereignisse vorstellte. In beiden Fällen war die Volksversammlung von den Volkstribunen einberufen worden. In der ersten ${ }^{30}$ forderte man Coriolan dazu auf, sich in Hinblick auf die von ihm im Senat gemachten Bemerkungen zu erklären. Er lehnte das ab und drängte zuerst die Beauftragten der Volkstribunen zurück, die versuchten, ihn festzunehmen, und danach mit Hilfe der Patrizier, die sich um ihn herum geschart hatten, die Aedilen, die dasselbe versuchten. Der Konflikt weitete sich nun auf die ganze Stadt aus und die Anhänger der beiden Parteien strömten auf das Forum. ${ }^{31}$ Doch es wurde kein unwiederbringlicher Schaden angerichtet und die Debatte wurde auf den folgenden Tag verschoben. Die zweite Episode folgte demselben Schema. ${ }^{32}$ Die Tribunen gerieten mit Coriolan aneinander. Seine hochmütigen Antworten führten zu einer ersten Konfrontation und die Plebejer entrüsteten sich, als die Patrizier ihm zustimmten. Das war der Zeitpunkt, an dem der Tribun L. Sicinius Vellutus versuchte, ihn zu verhaften und ihn vom Tarpeïschen Felsen herabzustürzen, um so die Gewalttaten zu sühnen, die er am Vortag gegen die Aedile begangen hatte. Der Aufruhr breitete sich aus. Plebejer und Patrizier traten sich gewaltbereit gegenüber ${ }^{33}$ und es bedurfte des Eingreifens der Konsuln, um sie voneinander $\mathrm{zu}$ trennen. Sicinius verzichtete auf sein Vorhaben, verwies die Angelegenheit an ein Verfahren in den Komitien (das er für eben diese Gelegenheit einführte) und entließ die Versammlung.

29 Diese Reihe gewalttätiger Konflikte, die die Geschichtsschreiber rekonstruierten, unterschieden sich ein wenig von dem allgemeinen Schema. In der zentralen Auseinandersetzung standen sich nämlich nicht die Magistrate als solche gegenüber, sondern die Magistrate und eine einzelne Persönlichkeit, die sich in der Zuhörerschaft befand und die sie verhaften wollten, die aber entweder die Bürger um sich scharte oder Gegenstand einer Auseinandersetzung zwischen Gegnern und Anhängern wurde. Der Unterschied änderte nichts am Ursprung des Konflikts, denn es waren immer noch die Magistrate, die dafür verantwortlich waren. Aber der direkte Hinweis auf einen Feind im Publikum schuf die Voraussetzungen für eine Mobilisierung, die nicht mehr anonym war, denn in gewisser Weise gewann sie einen Anführer.

Auf jeden Fall entwickelte sich aber diese Gewalt, die in den Versammlungen ausbrach, nicht über die Sitzung hinaus und führte nicht zu einem Umsturz der Institutionen. Sie endete oder beschwichtigte sich entweder mit der Auflösung der Versammlung, durch den Abzug oder die Flucht eines Teils der hauptsächlich Beteiligten oder durch das Einbrechen der Nacht, die weder Sieger noch Besiegte zurückließ. ${ }^{34}$ Die tieferen Gründe des Konflikts waren zwar nicht verschwunden, aber sie fanden ihre Lösung in weiteren 
Diskussionen und Entscheidungen, oder wenn das nicht der Fall war, riefen sie erneut Unruhen hervor, die sich in anderen Episoden fortsetzten.

Der Grund dafür lag darin, dass ganz genau so, wie der Konflikt zwischen den Magistraten die Quelle der Gewalt war, eben diese Magistrate die einzigen waren, die eine Lösung dafür finden konnten. Entweder lösten sie die Versammlung auf, oder sie beruhigten die Gewalt durch ihre Reden, oder sie trugen mit deren Hilfe einen Sieg über ihre Gegner davon. Aber außer ihnen konnte keine andere Persönlichkeit in den Vordergrund treten, Nutzen aus der Situation ziehen und sich an die Spitze eines Aufstands stellen. Selbst die Männer, die in den gerade von uns untersuchten Episoden in die Lage kamen, zu ihrer Verteidigung aktiv zu werden, wurden deswegen noch nicht zu Führern.

Dieser Umstand, der dem grundlegenden Zusammenwirken der republikanischen Institutionen entsprach, konnte den Geschichtsschreibern Schwierigkeiten bereiten, wenn sie sich eine Situation des Umsturzes vorstellen mussten, die eine illegale Übernahme der Macht nach sich zog.

Dafür findet man ein Beispiel unter den Lösungen, die Livius und Dionys von Halikarnass finden sollten, um die Ergreifung der Macht durch die Führer der Plebejer nach dem Tod der Virginia zu erklären. Livius ${ }^{35}$ stellte sich vor, dass Ap. Claudius nach dem Mord zunächst Verginius festnehmen lassen wollte, der jedoch flieht, und dann Icilius, den Verlobten des jungen Mädchens. Er ist gezwungen, sich selbst auf den Weg zu machen, um den Widerstand des jungen Mannes zu brechen. Dort stieß er mit L. Valerius Potitus und M. Horatius Barbatus zusammen, die seinen Liktoren zurückschlugen. Als er versuchte, die Menge in die Hand zu bekommen, und sie zu einer contio zusammenrief, folgten sie ihm auf die Tribüne und mobilisierten die Anhängerschaft der Menge ${ }^{36}$ so weitgehend, dass er gezwungen war zu flüchten. Dionys von Halikarnass ${ }^{37}$ gab eine geringfügig andere Version des Geschehens. Horatius und Valerius bemächtigten sich nicht der contio des Appius, sondern es war Valerius, der eine einberief und an einem anderen Ort als auf dem Forum. ${ }^{38}$ Die Konkurrenz zwischen den beiden Versammlungen schlug zum Vorteil des Valerius aus und Appius Claudius, der vom Volk im Stich gelassen wurde, verließ den Ort des Geschehens. Doch in beiden Fällen, sowohl in dem des Horatius wie dem des Valerius, handelte es sich um eine wirkliche Usurpation. Charakterisiert waren die beiden Männer durch ihre familiäre Abstammung, die sie mit den Konsuln des Jahres $509 \mathrm{v}$. Chr. verband, sowie durch die ihnen in den zwei vorangehenden Episoden zugeschriebenen Äußerungen mangelnden Einverständnisses. Livius und Dionys von Halikarnass rechtfertigten das lediglich mit dem Hinweis darauf, dass sie die Anführer des Widerstands gegen die Decemvirn geworden seien. ${ }^{39}$

Die Lektüre der Szenen der Gewalt, die Livius und Dionys von Halikarnass im Zusammenhang mit den Versammlungen der Römischen Republik rekonstruierten, ${ }^{40}$ bestätigt also die Beschreibung, die Cicero in seiner Rede Pro Sestio gegeben hatte. Die Konflikte hatten in den Meinungsverschiedenheiten unter den Magistraten ihren Ursprung. Die Erregung, die sie hervorriefen, verbreitete sich im Publikum, das einen der beiden unterstützte oder sich in Anhänger der einen oder anderen Seite aufspaltete. Der Streit konnte in Handgreiflichkeiten ausarten. Aber sofern der Einbruch der Nacht dem kein Ende setzte, konnten diese nur durch das Eingreifen der Amtsinhaber selbst beendet werden. Diejenigen, die für den Ausbruch der Gewalt verantwortlich waren, waren auch für deren Beendigung verantwortlich. Die Gewalt 
war auf diese Weise auf den institutionellen Rahmen der Versammlung beschränkt. Sie beeinträchtigte diese manchmal oder hinderte sie, wenn auch nur vorläufig, an ihrer geordneten Durchführung. Aber sie führte doch nicht zu ihrem Umsturz. Der Fall einer Usurpation blieb außerordentlich und fiktiv. Die Gewalt war so eine der erwarteten Dimensionen des römischen politischen Systems, denn sie war eine der Folgen der Ebenbürtigkeit der Macht zwischen Kollegen und des Fehlens einer Instanz der Schlichtung.

Es versteht sich, dass dieses Paradigma des Entstehens von Gewalt in den Versammlungen allgemein bekannt war und von daher einen, wenn auch nicht erwünschten, so doch allseits akzeptieren Mechanismus der Beteiligung der Bürger am politischen Leben darstellte. Kein Politiker konnte der Versuchung entgehen, von ihr Gebrauch zu machen, noch der Notwendigkeit, sie zu kontrollieren. Diese Tatsache hatte mehrere Folgen. Die erste war, dass es am Vorabend einer wichtigen Versammlung, die Gefahr lief, zu einer Auseinandersetzung zu führen, angebracht war, sich darauf vorzubereiten und sich zu organisieren. Man traf Maßnahmen, die zunächst vielleicht nur eine Vorsorge waren, aber doch offensiv werden konnten. Eine gewisse Erfahrung und Fähigkeit im Umgang mit der Gewalt entstand. Die zweite Folge war, dass im Rahmen der Zunahme und Verstärkung der Konflikte, die das Ende der Republik kennzeichneten, die Situationen der Auseinandersetzung immer extremer wurden und dass es eine gewisse Steigerung im Rückgriff auf diese Methoden gab. Gehorchten sie damals immer noch dem von Cicero definierten Schema? Das ist die Frage, die wir uns stellen können und die uns dazu bringen sollte, die Gültigkeit des Schemas zu überprüfen.

Eine erste Regel drängte sich jedem Amtsinhaber auf, wenn er sicher sein wollte, die Gewalt zu meistern, die bei einer Versammlung aufzukommen drohte, an der er teilnahm, und die er eventuell gegen seine Gegner nutzen wollte: er musste die räumliche Dimension gut unter Kontrolle halten, indem er die Plätze, an denen die Versammlung stattfinden sollte, durch seine Gefolgsleute besetzen ließ. Im Falle der Komitien war das sogar eine doppelte Notwendigkeit, denn zur Absicht, die Gewalt zu beherrschen, kam noch die hinzu, einerseits seine Gefolgsleute zu mobilisieren, die ihre Stimme im gewünschten Sinne abgaben, und andererseits die seines Gegners daran zu hindern, das ihrerseits zu tun. ${ }^{41}$ Die beiden Ziele waren gewissermaßen miteinander verbunden. Die Anzeichen dafür zeigen sich bereits in bestimmten Episoden der archaischen Zeit, die Livius oder Dionys von Halikarnass rekonstruieren. Das bedeutet, dass in ihren Augen die entsprechende Vorsorge eine Regel war. Aber in den kürzer zurückliegenden Konflikten wird das Phänomen am deutlichsten.

Das beste Beispiel ${ }^{42}$ liefern uns die Szenen der Gewalt, die den Morden an Tiberius und Caius Gracchus vorangingen. Unsere hauptsächlichen Quellen, Appian und Plutarch, folgten ein wenig unterschiedlichen Überlieferungen und wichen in der Bekräftigung der Verantwortung der Gracchen voneinander ab. In ihren Berichten wurde so die vorherige Besetzung des Ortes der Versammlung zum Anzeichen für eine Vorbereitung zur Gewalt. Plutarch, der den Gracchen mehr zugeneigt war, deutet für die Versammlung, die dem Tod des Tiberius Gracchus voranging, keinerlei Maßnahme dieser Art an, und wenn in seiner Version die Gefolgsleute des Caius Gracchus die area Capitolina am frühen Morgen des Tages der Abstimmung über die Aufhebung des Gesetzes zur Gründung einer Kolonie in Karthago besetzt hatten, hatten die Anhänger des Opimius doch das Gleiche getan. ${ }^{43}$ Die Verantwortung für den Ausbruch der 
Zwischenfälle war also geteilt. Appian machte im Falle des Caius Gracchus keinerlei Angaben, aber nach dem Bericht, den er vom Tode des Tiberius Gracchus gibt, habe dieser in der Nacht vor dem Tag der Abstimmung, die ihm seine Wiederwahl sichern sollte, seine Anhänger um sich versammelt, habe mit ihnen ein Zeichen für den Fall vereinbart, dass man kämpfen sollte, und habe zugleich das Podium des Tempels des Iuppiter Capitolinus besetzt sowie die zentrale area, wo die Versammlung sich einfinden sollte. ${ }^{44} \mathrm{Er}$ bereitete sich so auf die Gewalt vor, die ausbrechen würde, und sah sie sogar voraus.

Es kann kein Zweifel daran bestehen, dass die Vorstellungen, die die genannten Historiker und ihre Quellen bei den vorgenommenen Rekonstruktionen leiteten, nicht den realen Vorgängen entsprachen. Die Kontrolle des Ortes war danach eine Voraussetzung für die Kontrolle der Gewalt. Außerdem musste man in der Lage sein, über Anhänger zu verfügen, die bereit waren sich einzusetzen. Das Problem war leicht zu lösen, wenn diejenigen, die durch die vorgeschlagenen Maßnahmen begünstigt wurden, sich ihren Förderern zur Verfügung stellen, und wenn über die Klientelen einsatzbereite Anhänger mobilisiert werden konnten. Die Berichte bei Livius und Dionys von Halikarnass ließen bereits die häufig wiederkehrende Spaltung zwischen Patriziern und Plebejern erkennen und die daraus folgenden spontanen Aufläufe, von denen die verschiedenen Hauptakteure profitieren konnten. Der Prozess des Postumius von Pyrgi hatte die Mobilisierung der Publikanen zur Verteidigung ihres Kollegen vorgeführt. Solche Bezeugungen der Solidarität konnten im Vorhinein vorbereitet werden, eine Inszenierung und Entwicklung mit verteilten Rollen, die die wichtigsten Akteure übernahmen. ${ }^{45}$

Der Bericht, den Appian ${ }^{46}$ von dem Verhalten gab, das die Parteigänger des Tribunen Sulpicius Rufus im Jahre $88 \mathrm{v}$. Chr. gegen die Konsuln Sulla und Pompeius Rufus an den Tag legten, liefert ein gutes Beispiel für diese im Vorhinein geplante Organisation der Gewalt. Die beiden Konsuln hatten ein iustitium beschlossen, das die Abstimmung über die Gesetzesvorschläge des Tribunen blockierte. Sulpicius Rufus ließ das Forum gleich zu Beginn von Männern besetzen, die mit Dolchen bewaffnet waren. Sobald die Versammlung zusammengetreten war, nahm er die Konsuln zur Seite und ersuchte sie, das iustitium aufzuheben. Der Konflikt zwischen den Magistraten rief einen Tumult unter dem Publikum hervor. Die Gefolgsleute des Tribunen bedrohten dann die Konsuln, bis diese die Versammlung verließen.

Die Abfolge der Ereignisse entspricht also ganz und gar dem ciceronianischen Schema. Man stellt sich offensichtlich die Frage, ob diese Übereinstimmung ein Ergebnis der Realität war oder die Frucht der Vision, die Appian und seine Quellen von dem Ereignis hatten. Aber muss man wirklich zwischen diesen Alternativen wählen? Es ist doch wahrscheinlicher, dass das Paradigma, wenn es sich dem Erzähler aufdrängte, auch für die Handelnden bestimmend war.

Das ist es zumindest, was Episoden in der gleichen Zeit der 60er und 50er Jahre v. Chr. vermuten lassen, die von Szenen der Gewalt berichten, die mindestens so heftig oder sogar noch heftiger waren als die, die gerade erwähnt worden sind. Unter dem Eindruck der Verschärfung der allgemeinen Krise, die die Römische Republik durchzog, gewannen die Spannungen und Auseinandersetzungen an Häufigkeit und Stärke. ${ }^{47}$ Der Höhepunkt wurde ohne Frage in den 50er Jahren unter dem Einfluss des Bündnisses von Pompeius, Caesar und Crassus und dem Tribunat des Clodius erreicht. Vor allem Letzterer baute eine Organisation seiner Anhänger auf, die es ihm erlaubte, diese mit 
größerer Wirksamkeit zu mobilisieren und einzusetzen. Man erinnert sich da an die Rekrutierungskampagnen, die er im Jahre $58 \mathrm{v}$. Chr. in aller Öffentlichkeit auf dem Forum veranstaltete,$^{48}$ und allgemeiner an die Rolle seiner Mittelsmänner bei der Aufstellung der Banden seiner Anhänger, die er unter der städtischen Plebs hatte mobilisieren können. ${ }^{49}$ In Zusammenhang dieser Ereignisse nahmen die Prügeleien und Handgreiflichkeiten ein unerwartetes Ausmaß an. Sie breiteten sich auf alle Bereiche des sozialen Lebens aus und ereigneten sich wohlgemerkt auch außerhalb des besonderen Rahmens der Versammlungen. Aber in diesem besonderen Fall fügten sie sich doch weiterhin in das ciceronianische Schema ein.

Die Szenen der Gewalt, die im Jahre 59 v. Chr. die Abstimmung über das Agrargesetz Caesars begleiteten, geben ein gutes Beispiel für die neue Situation ab. Die reichhaltigsten Angaben liefert uns Cassius Dio..$^{50}$ Der allgemeine Zusammenhang war durch den Konflikt zwischen Caesar und Bibulus gekennzeichnet. Letzterer hatte bereits versucht, sich der Verabschiedung des Gesetzes zu widersetzen, und zwar so erfolgreich, dass die Konfrontation unvermeidlich war. Die Anhänger Caesars besetzten in der Nacht vor dem Tag der Abstimmung das Forum. Bibulus, der sich mit seinen Anhängern dorthin begab, war gezwungen, sich den Durchgang zu erzwingen. Doch man ließ ihn bis zur Tribüne durch, und das war ein Anzeichen dafür, dass seine Anwesenheit legitim und erwartet war. ${ }^{51}$ Es war in der Tat notwendig, dass das institutionelle Verfahren seinen Anfang nahm. Aber sobald er das Wort ergriffen hatte, um sich dem Vorschlag zu widersetzen, kam es zum Ausbruch von Gewalt: seine Liktorenbündel wurden zerbrochen und die Tribunen, die ihn begleiteten, wurden verwundet. Appian, der die Episode ebenfalls erwähnt, ${ }^{52}$ fügt hinzu, dass er die Treppe heruntergestürzt wurde und dass Cato seinerseits den Durchgang erzwang und versuchte, das Wort zu ergreifen, aber auch er wurde vertrieben. Sobald die Gegner kaltgestellt waren, wurde das Gesetz beschlossen. Diese ganze Gewalttätigkeit war offensichtlich ganz bewusst im Voraus geplant worden, sowohl in der vorangehenden Besetzung des Platzes wie in der Organisation der Banden von Anhängern. Aber das allgemeine Schema des Ablaufs der Ereignisse folgte doch immer noch der von Cicero beschriebenen Abfolge: Auseinandersetzung - Aufruhr in der Zuhörerschaft - Spaltung - verbale oder physische Gewalt - Ende der Episode. Das einzige, was fehlte, war die Spontaneität. Jeder Augenblick war in der Tat vorbereitet. Das bestätigt neuerlich, dass das Paradigma sich in den Köpfen durchsetzte und die Verhaltensweisen strukturierte.

Ein weiteres Beispiel lässt das klar zutage treten. Es handelt sich um die Zwischenfälle, die im Jahre 62 v. Chr. die rogatio des Tribunen Q. Caecilius Metellus Nepos begleiteten, der mit Unterstützung Caesars die Rückkehr des Pompeius erreichen wollte, um mit den Folgen der Verschwörung des Catilina fertig zu werden. Zwei andere Tribunen, Cato und Minucius Thermus, widersetzten sich dem. Wenn man Plutarch ${ }^{53}$ Glauben schenken will, fanden die beiden Männer, als sie zur Rostra des Tempels des Castor und Pollux kamen, den Platz von Metellus und Caesar besetzt, die so dicht von bewaffneten Männern umgeben waren, dass man sich kaum einen Durchgang verschaffen konnte. Der Konflikt brach aus, als Cato und Minucius sich dagegen wehrten, dass der Schreiber die rogatio vorlas. Da begann Metellus sie selber vorzulesen. Cato riss ihm den Text aus der Hand. Aber Metellus, der diesen Eingriff vorausgesehen hatte, hatte den Text auswendig gelernt und trug ihn weiter vor. Daraufhin hinderte ihn Minucius am Sprechen. Nach Cassius Dio ${ }^{54}$ entwickelte sich daraufhin ein Handgemenge. Nach dem Bericht des Plutarch rief Metellus Verstärkung aus seinem Lager herbei ${ }^{55}$ Jedenfalls 
ergriff die Gewalttätigkeit die gesamte Versammlung, aber nach verschiedenen wechselnden Ereignissen behielten Cato und seine Anhänger die Oberhand.

Diese Episode ähnelt sehr stark der Affäre, die fünf Jahre vorher das Tribunat des Cornelius ausgezeichnet hatte. Letzterer hatte, wie bereits erwähnt, das seinem praeco erteilte Verbot der Verlesung seiner rogatio dadurch umgangen, dass er den Text selbst verlas, was Anlass zu Gewalttätigkeit gegeben hatte. In der Tat deutet das Verhalten der Hauptbeteiligten des Jahres 62 darauf hin, dass sie eine Wiederholung der Ereignisse des Jahres 67 vorausgesehen hatten: die Tribunen waren zur Steigerung der Behinderungen bereit, die Örtlichkeiten waren von bewaffneten Banden besetzt und Verstärkung stand in der Nähe bereit. Die Struktur der Ereignisse änderte sich nicht. Die Antizipation und Vorbereitung der Gewalt gab ihnen lediglich größere Bedeutung und Intensität.

Wir belassen es bei diesen wenigen Beispielen. Es sollte nur an die Art und Weise erinnert werden, in der Clodius die Gewalt während des Prozesses gegen Milo im Jahre $56 \mathrm{v}$. Chr. organisiert hatte. Er hatte im Vorhinein ein Spiel von Fragen und Antworten vorbereitet, das für Pompeius äußerst beleidigend war, und seine eigenen Männer antworteten jeweils auf diese Fragen, die er ihnen von der Höhe der Tribüne entgegenschleuderte. Das blieb indes vergeblich, denn die Anhänger des Pompeius reagierten darauf und trugen den Sieg davon..$^{56}$ Es handelte sich also um die Befolgung bereits festgelegter Anweisungen, wenn die Auseinandersetzung zwischen den auf der Rostra anwesenden Magistraten auf die Versammlung übergriff. Der Aufruhr hatte auch hier keinerlei Spontaneität mehr. Das Handgemenge war von der einen wie der anderen Seite vorausgesehen und vorbereitet worden bis hin zu der Art, wie das Publikum reagieren sollte, ohne dass dabei die Gültigkeit des Paradigmas in Frage gestellt wurde.

Eine letzte Bemerkung wird erlauben, noch zu unterstreichen, bis zu welchem Grade dieses Modell des kollektiven Verhaltens sich bei den Akteuren am Ende der Republik sogar dann aufdrängte, wenn sie die Gewalt organisierten, um sich gegenüber ihren Gegnern durchzusetzen. Die Zusammenstöße, die zur Ablehnung des von Fabricius eingebrachten Vorschlags zur Sicherung der Rückkehr Ciceros führten, wurden durch die Besetzung der Orte durch die verschiedenen Hauptbeteiligten vorbereitet. Wenn man Cicero Glauben schenken will, dessen Bericht trotz allem doch der Wahrheit nahekommen sollte, ${ }^{57}$ richtete Fabricius sich kurz vor Morgengrauen auf der Rostra ein. ${ }^{58}$ Seine Gegner, d. h. die Männer des Clodius und vielleicht auch Clodius selbst, hatten sich bereits im Laufe der Nacht des Forums, der Kurie und des comitium bemächtigt. ${ }^{59}$ Was hätte sie daran gehindert, auch die Rostra zu besetzen, wenn nicht ein gewisser Respekt vor den institutionellen Formen? Ohne Zweifel dachten sie, dass sie den Anbruch des Tages und einen Beginn der von Fabricius initiierten Prozedur abwarten sollten, um den gewaltsamen Kampf zu entfesseln, den Cicero beschrieb. Wie im Falle des Agrargesetzes Caesars musste ohne Zweifel erst einer der Hauptbeteiligten das Wort ergreifen, bevor der Widerstand entbrannte. Dieser Zwang zur Zurückhaltung musste also stark sein, wenn diese Männer dazu gebracht wurden, nur einige Meter voneinander entfernt zu warten, vorbereitet auf den Kampf, der sie aufeinanderprallen lassen sollte, aber trotzdem bemüht, den Anschein zu wahren, der ihren Handlungen eine gewisse Legitimität verleihen sollte. den Vergleich, den Cicero zwischen den üblichen, weil unvermeidlichen Formen der 
Gewalt in den Volksversammlungen zog und jener gewalttätigen Auseinandersetzung, die zu Toten geführt hatte und in der, wie er sagte, sein Bruder riskiert hatte, sein Leben zu verlieren. Wo lag der Unterschied? Ohne Frage ist er nicht in dem Gesamtschema einer Auseinandersetzung zu finden, die zunächst die Magistrate betraf und sich dann unter dem Publikum ausbreitete, dessen Verhalten er, wie wir gesehen haben, ebenso passend organisierte wie in den Rekonstruktionen der Annalisten. Er bestimmte auch im Voraus das Verhalten derer, die ihren Willen mittels Gewalt durchsetzen wollten. Das Neue an dieser Krise, die das Ende der Republik besiegeln sollte, war ganz einfach, dass die Notwendigkeit, den Sieg über die Gegner davonzutragen, aus diesem Rückgriff auf die Gewalt ein vorbereitetes und kontrolliertes Mittel gemacht hatte, das an Kraft und Intensität gewonnen hatte.

Welche Folgerung kann man zum Schluss aus den vorangehend gemachten Bemerkungen ziehen? Die deutlichste Schlussfolgerung ist, dass die von Cicero in der Rede Pro Sestio gegebene Beschreibung der Formen von Entfesselung und Ausbreitung der Gewalt in den römischen Volksversammlungen der Realität eines Modells kollektiven Verhaltens entsprach. Es stand im Einklang mit den verlässlichsten Beschreibungen, strukturierte die Rekonstruktionen der Annalisten und bürdete seine Zwänge selbst denen auf, die den Kampf suchten und vorbereiteten. Cicero legte damit Zeugnis darüber $a b$, dass die Gewalt eine erwartete Dimension der Abläufe der römischen Institutionen war. Selbst wenn sie mehr befürchtet als erwünscht war, war sie doch immer eine Möglichkeit am Horizont der politisch Andersdenkenden und lief stets Gefahr auszubrechen, selbst in Zeiten relativen bürgerlichen Friedens. In den Volksversammlungen entstand sie auf Initiative der Magistrate und insbesondere aufgrund der Auseinandersetzungen, die diese in Gegensatz zueinander brachten, und einzig und allein dadurch. Sie breitete sich dann in der Zuhörerschaft aus, die sich äußerte, möglicherweise unterschiedlicher Meinung war und deshalb aneinandergeriet. Dann und nur dann konnten die Verbindungen und Zusammengehörigkeitsgefühle zum Tragen kommen. Wer auch immer sich auf Handgreiflichkeiten vorbereiten wollte, sei es, um dem Angriff eines Gegners zu widerstehen, sei es, um sich im Gegenteil durch Rückgriff auf Gewalt durchzusetzen, musste sowohl seine Anhänger organisieren, als auch die Orte besetzen. Das Ziel war nicht, die Gegner niederzumetzeln, sondern sie zu einem Rückzug zu zwingen, der der Verabschiedung der gewünschten Entscheidungen freien Raum ließ.

Eine solche Situation ergab sich offensichtlich daraus, dass das gleiche Ausmaß an Macht, das die Kollegialität mit sich brachte, keine wirkliche Instanz eines Schiedsgerichts kannte, das erlaubt hätte, in offenen Konflikten zu entscheiden. Weder der Senat noch das Volk konnten eine Entscheidung treffen, wenn man sie nicht anrief. Und nur manchmal konnte das Eingreifen des Senats einen gewissen Erfolg haben. Die Betrachtung all dieser Episoden zeigt auch deutlich, dass die Rolle der Magistrate außerordentlich entscheidend war. In deren Gegensätzen hatte die Gewalt ihren Ursprung, und nur hier. Wir wussten das bereits vorher, aber hier ist eine Bestätigung der Tatsache, dass die Magistrate die einzigen wirklichen Akteure des politischen Lebens waren, denn sie waren es, die über die wirkliche Initiative verfügten.

Diese Bemerkungen führen auch zu einer etwas allgemeineren Überlegung. Dieses kollektive Verhalten, das die Art bestimmte, in der die Handelnden in der Politik auf die Gewalt zurückgriffen, nahm den Weg über die Abläufe der Versammlungen: Vorrang und Initiative der Magistrate, Reaktion und Antworten des Volkes, eventuell 
Aufspaltung in unterschiedliche Kategorien. Wie bereits ausführlich untersucht wurde, ${ }^{60}$ verstanden sich die Versammlungen als großartige Rituale des Austauschs mit der Aristokratie und der Zustimmung zu den wesentlichen Grundlagen der Funktionsweise der Stadt. Der Umstand, dass die von Spannungen und Konflikten hervorgerufenen Verhaltensweisen die Semantik respektierten, zeugt von dem hohen Grad an Verinnerlichung, mit der diese Mechanismen der Integration zum Grundbestand der bürgerlichen Identität gehörten. ${ }^{61}$ Die kollektive Gewalt der einfachen Schichten wendete sich nicht gegen die Institutionen. Sie stellte sie nicht in Frage. Sie nutzte ihre Strukturen.

\section{BIBLIOGRAPHIE}

Benner, H. (1987): Die Politik des P. Clodius Pulcher. Untersuchungen zur Denaturierung des Clientelwesens in der ausgehenden römischen Republik (Historia Einzelschrift, Bd. 50), Stuttgart. De Libero, L. (1992): Obstruktion. Politische Praktiken im Senat und in der Volksversammlung der ausgehenden römischen Republik (70-49 v. Chr.) (Hermes Einzelschrift, Bd. 59), Stuttgart.

Earl, D. C. (1963): Tiberius Gracchus. A Study in Politics (Latomus, Bd. 66), Brüssel.

Flaig, E. (2001), »L'assemblée du peuple à Rome comme rituel de consensus. Hiérarchie politique et intensité de la volonté populaire«, ARRS, 140 (4), S. 12-20.

Flaig, E. (2003): Ritualisierte Politik, Zeichen, Gesten und Herrschaft im Alten Rom, Göttingen.

Gabba, E. (Hg.) (1967): Appiani Bellorum Civilium liber primus, Florenz.

Griffin, M. (1973): »The Tribune C. Cornelius«, JRS, 63, S. 196-213.

Hahn, I. (1975): „Der Klassenkampf der plebs urbana in den letzten Jahrhunderten der römischen Republik«, in: Herrmann, J. / Sellnow, I. (Hg.): Die Rolle der Volksmassen in der Geschichte der vorkapitalistischen Gesellschaftsformationen, Berlin, S. 121-146.

Hiebel, D. (2009): Rôles institutionnels et politique de la contio sous la République romaine (287-49 av. J.C.), Paris.

Hopkins, K. (1991): »From Violence to Blessing: Symbols and Rituals in Ancient Rome«, in: Molho, A. / Raaflaub, K. / Emlen, J. (Hg.): City States in Classical Antiquity and Medieval Italy, Stuttgart, S. 479-498.

Jehne, M. (2003): »Integrationsrituale in der Römischen Republik. Zur einbindenden Wirkung der Volksversammlungen «, in: Hölkeskamp, K.-J. / Rüsen, J. / Stein-Hölkeskamp, E. / Grütter, H. Th. (Hg.): Sinn (in) der Antike, Orientierungssysteme, Leitbilder und Wertkonzepte im Altertum, Mainz, S. 279-297.

Laser, G. (1997): Populo et scaenae serviendum est. Die Bedeutung der städtischen Masse in der späten Römischen Republik, Trier.

Lintott, A. (1999): Violence in Republican Rome, 2. Aufl., Oxford.

Metaxaki-Mitrou, F. (1985): »Violence in the Contio during the Ciceronian Age, AC, 54, S. 180-187. 
Moreau, Ph. (2003): „Donner la parole au peuple? Rhétorique et manipulation des contiones à la fin de la République romaine«, in: Bonnafous, S. / Chiron, P. / Ducard, D. / Levy, C. (Hg.):

Argumentation et discours politique. Actes du colloque international de Cerrisy-la-Salle, Rennes, S. 175189.

Morstein-Marx, R. (2004): Mass Oratory and Political Power in the late Roman Republic, Cambridge.

Mouritsen, H. (2001): Plebs and Politics in the late Roman Republic, Cambridge.

Nippel, W. (1981): „Die plebs urbana und die Rolle der Gewalt in der späten römischen Republik«, in: Mommsen, H. / Schulze, W. (Hg.): Vom Elend der Handarbeit. Probleme historischer Unterschichtenforschung, Stuttgart, S. 70-92.

Nippel, W. (1988): Aufruhr und »Polizei« in der römischen Republik, Stuttgart.

Pina Polo, Fr. (1996): Contra arma verbis. Der Redner vor dem Volk in der späten römischen Republik, Stuttgart.

Rilinger, R. (1989): »Loca intercessionis und Legalismus in der späten Republik«, Chiron, 19, S. 481498.

Schneider, H. (1982-1983): »Die politische Rolle der plebs urbana während des Tribunats des $L$. Appuleius Saturninus«, Anc. Soc., 13-14, S. 193-221.

Smith, R. E. (1977): »The Use of Force in Passing Legislation in the Late Republic«, Athenaeum, 55, S. $150-174$.

Sumi, G. S. (1997): »Power and Ritual: the Crowd at Clodius' Funeral«, Historia, 46, S. 80-102.

Tatum, W. J. (1999): The Patrician Tribune. Publius Clodius Pulcher, Chapel Hill u. London.

Thommen, L. (1995): „Les lieux de la plèbe et de ses tribuns dans la Rome républicaine«, Klio, 77, S. $358-370$

Vanderbroeck, P. J. J. (1987): Popular Leadership and Collective Behaviour in the Late Roman Republic (ca. 80-50 B.C.), Amsterdam.

Zecchini, G. (1978): »L'opposizione a Cesare nel 59 nell'interpretazione storiografica ottimate«, in: Sordi, M. (Hg.): Aspetti dell'opinione pubblica nel mondo antico (Contributi dell'Istituto di Storia Antica, Bd. 5), Mailand, S. 98-110.

\section{NOTES}

1. Cic. Sest. 77.

2. Vgl. Cic. Leg. 3,42, der auf diesem Punkt bestand, als er den Rückgriff auf Gewalt in den Versammlungen ablehnte und bestätigte, dass sie allein in der Verantwortung der Magistrate lag: »Deinceps sunt cum populo actiones, in quibus primum et maximum: vis abesto. Nihil est enim exitiosius civitatibus, nihil tam contrarium, iuri ac legibus, nihil minus civile et inhumanius, quam in composita et constituta re publica quicquam agi per vim. [...] Invito eo qui cum populo ageret seditionem non posse fieri, quippe cui liceat concilium, simul atque intercessum turbarique coeptum sit, dimittere. Quod qui permittit, quom agi nihil non potest, vim quaerit, cuius impunitatem amittit hac lege.« Über die Quellen der Blockierung s. Rilinger (1989); De Libero (1992), S. 43 f., mit der Tendenz, die Wirkung der Interzessionen bei der Entfesselung der Gewalt zu untertreiben. Zu der Bewertung der Gewalt durch Cicero s. Lintott (1999), S. 53-64. 
3. Die Verantwortung der Magistrate in den kollektiven Verhaltensweisen ist zutreffend unterstrichen bei Vanderbroeck (1987), S. 124-130, und in den contiones vgl. auch Hiebel (2009), S. 94-103.

4. Zur Gewalt in den Versammlungen s. vor allem Nippel (1981); Metaxaki-Mitrou (1985); Lintott (1999), S. 69-73; Vanderbroeck (1987), S. 147; Nippel (1988), S. 56-58, der die Verbindung von obnuntiatio und Gewalt besonders klar erkannt hat.

5. Er schloss (Cic. Sest. 77) den Vergleich zwischen der üblichen Situation und der des Jahres 57 mit den folgenden Worten ab, die zwei Arten von Versammlungen in Verbindung miteinander brachte: "nullo vero verbo facto, nulla contione advocata, nulla lege lata concitatam nocturnam seditionem quis audivit?«.

6. Zu diesen Fragen vgl. vor allem Lintott (1999), passim.

7. Sall. Iug. 34: „Tametsi multitudo quae in contione aderat vehementer accensa terrebat eum clamore, voltu, saepe inpetu atque aliis omnibus quae ira fieri amat, vicit tamen inpudentia. Ita populus ludibrio habitus ex contione discedit [...].»

8. Cass. Dio 36,30,24-36; Plut. Pomp. 25. Cassius Dio folgt hier mit Sicherheit der Rede Pro Cornelio des Cicero (vgl. Ascon, p. 71-71C.). Vgl. dazu Vanderbroeck (1987), S. 224.

9. Appian scheint hier die sicherere Quelle zu sein, vgl. Gabba (1967) ad loc.

10. Diod. 34-35,6.

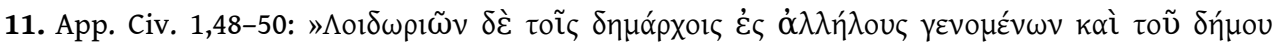

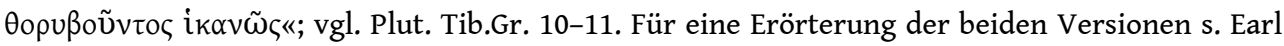
(1963), S. 82-85.

12. Asc. p. 58-59C: "Quod cum improbe fieri C. Piso consul vehementer quereretur tollique tribuniciam intercessionem diceret, gravi convicio a populo exceptus est «. Ihm folgt Cass. Dio 36,39,3-4. Vgl. Cic. Vatin. 5 zu diesem Punkt. Vgl. Vanderbroeck (1987), S. 225 f., und zum allgemeinen Zusammenhang Griffin (1973).

13. Cass. Dio a.O.

14. Liv. 25,3,13-19.

15. Das versichert Livius, vielleicht in der Absicht, die Ereignisse zu dramatisieren. Oder vielleicht weigerte er sich wirklich. In diesem Falle würde sich der Konflikt, der aus dem Gegensatz zwischen den Tribunen entsprungen war, in die Versammlung verlagern.

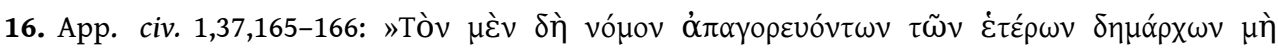

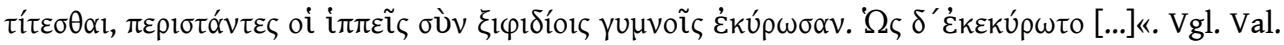
Max. 8,6,4.

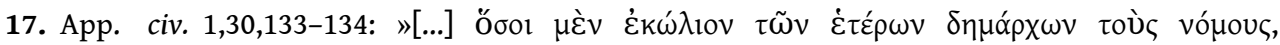

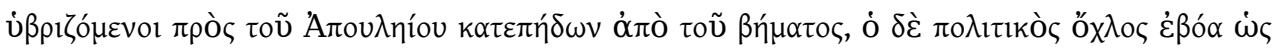

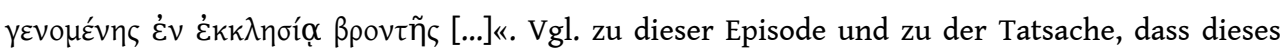
Gesetz per vim lata war, Cic. Sest. 37; Liv. Per. 69; Vir. ill. 73,7.

18. Vgl. App. civ. 1,29,132. Vgl. das vorangehende Beispiel des weiter oben genannten Agrargesetzes des Tiberius Gracchus (Diod. 34-35,6) und Lintott (1999), S. 178 f.

19. Vgl. insbesondere die Zweifel von Schneider (1982-1983); s. auch Vanderbroeck (1987), S. 72.

20. Rhet. Her. 1,21: "Saturninus ferre coepit, collegae intercedere. Ille nihilominus sitellam detulit. Caepio, ut illum contra intercedentibus collegis, adversus rem publicam vidit ferre, cum viris bonis impetum facit, pontes disturbat, cistas deicit, inpedimento est quo setius feratur [...]«; vgl. a.a.0. 2,17.

21. Zu den allgemeinen Umständen der Mobilisierung s. Vanderbroeck (1987), S. 81-103 und 112116.

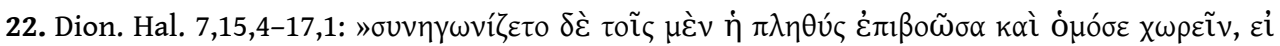

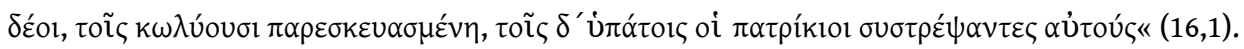

23. Liv. 2,56-57; Dion. Hal. 9,41 (für die vorangehenden Episoden); 43-49.

24. Liv. 2,56,10; vgl. Dion. Hal. 9,41,5, aber für eine vorangehende Versammlung; 44,3. 
25. Liv. 2,56,14 : "violatusque esset tribunus ni et contio omnis atrox coorta pro tribuno in consulem esset, et concursus hominum in forum ex tota urbe concitatae multitudinis fieret «. Vgl. Dion. Hal. 9,48, der an eine direkte Konfrontation zwischen dem Tribunen Laetorius und dem Konsul Ap. Claudius denkt, die beide ihre Parteigänger mobilisierten.

26. Dion. Hal. 10,40-41.

27. Vgl. auch für andere Szenen der Verhaftung, die von Gewalttätigkeiten begleitet werden, Liv. 2,29; 2,55; 3,45-46; 3,48-49; Dion. Hal. 11,12 (die Affäre der Virginia).

28. Liv. 8,32-33; vgl. Val. Max. 2,7,8; Vir. ill. 31; Frontin. Strat. 4,1,39; Eutrop. 2,8.

29. Liv. 8,32,11-12: »Fabius fidem militum implorans lacerantibus vestem lictoribus ad triarios tumultum iam in contione miscentes sese recepit. Inde clamor in totam contionem est perlatus; alibi preces, alibi minae audiebantur«.

30. Dion. Hal. 7,26; Plut. Coriol. 17,4-6 folgt demselben Schema; vgl. auch Liv. 2,35.

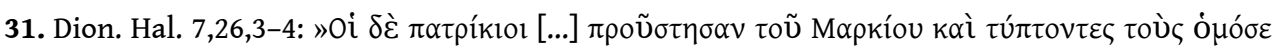

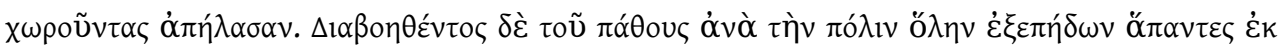
$\tau \tilde{\omega} v$ oikı $\tilde{\omega} v[. ..] . \lll$

32. Dion. Hal. 7,27-36; Plut. Coriol. 17,7-18.

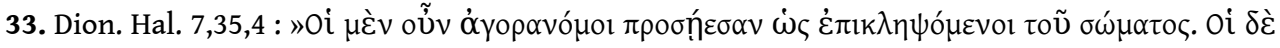

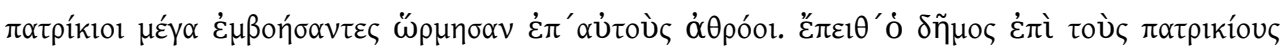
[...].«

34. Vgl. Liv. 3,17,9; 8,33,2; Dion. Hal. 7,16,2; 9,41,4; 9,48,3; Plut. Coriol. $17,7$.

35. Liv. 3,49,1-5.

36. Liv. 3,49,4: In contionem Appius escendit : sequuntur Horatius Valeriusque; eos contio audit, decemviro obstrepitur«.

37. Dion. Hal. 11,38,5-39,4.

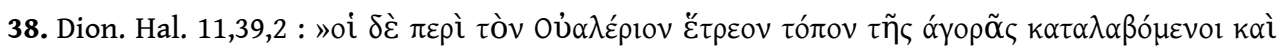

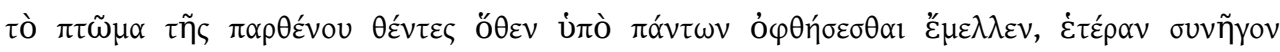

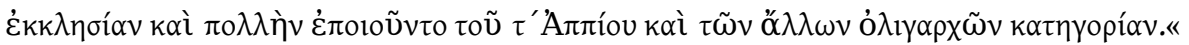

39. Liv. 3,49,3 : »sed duces quoque multitudinis erant«; vgl. 3,39-41; Dion. Hal. 11,38,5:

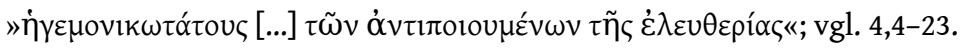

40. Außer den bereits zitierten Fällen s. noch Liv. 3,17.

41. Vgl. Cic. Att. 4,3,4; Liv. 45,36,6; Plut. Tib.Gr. 18,1. Zum Fassungsvermögen des Forums und der Wirkung einer im Vorhinein erfolgten Besetzung s. Thommen (1995), S. 358-370, besonders S. $364 \mathrm{f}$.

42. $\mathrm{Zu}$ den hier untersuchten Episoden kann man noch die Abstimmung über den Triumph des Aemilius Paulus im Jahre 167 v. Chr. hinzufügen (Liv. 45,36,6-10; Plut. Aem.P. 30,8-31,4), die Gewalttätigkeiten, die den Tod des C. Memmius im Jahre $100 \mathrm{v}$. Chr. begleiteten (App. BC 1,32,142-143), den Konflikt über die Verteilung der Neubürger im Jahre 87 v. Chr. (App, BC 1,64,288-292), den Vorschlag des Manilius eines Gesetzes zur Verteilung der Freigelassenen auf die Tribus im Jahre 67-66 v. Chr. (Ascon. p.45C; Cass. Dio 36,42; vgl. Vandenbroeck [1987], S. 227), das Gesetz des Clodius de capite civis gegen Cicero im Jahre 58 v. Chr. (Cic. Pro Sest. 53), den Widerstand des Sestius während einer Versammlung des Jahres 57 v. Chr. (Cic. P.red.Sen. 7; Cic. P.red.Pop. 14; Cic. Pro Sest. 78-80; Cic. Pro Mil. 38; vgl. Vandenbroeck [1987], S. 245 f.), die Abhaltung einer Versammlung zugunsten des Pompeius im Jahre 566 v. Chr. (Plut. Cat. min. 43,1-7; Cass. Dio 39,34-35; Vanderbroeck [1987], S. 257 f.) und die Gewalttätigkeiten in den Versammlungen während des Prozesses des Milo (Cic. Pro Mil. 91; App. BC 2,22,79-83; vgl. Vandenbroeck [1987], S. 264).

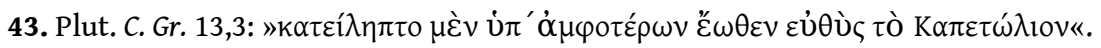




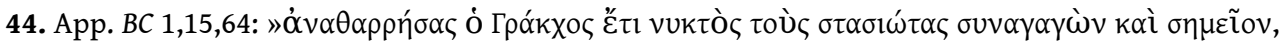

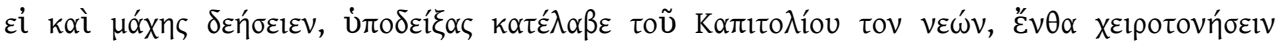

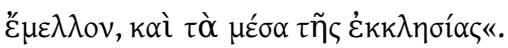

45. Vgl. insbesondere zur Organisation der Gewalt Lintott (1999), S. 74-85; Vanderbroeck (1987), S. 52-66; S. 81-103; S. 112-116; S. 124-130; S. 150-152.

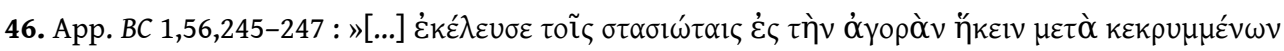

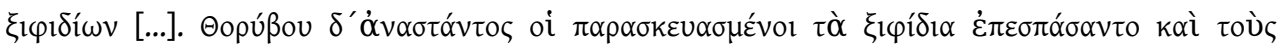

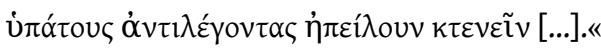

47. Vgl. dazu allgemein Hahn (1973), S. 121-146 und insbesondere S. 136 f.; Smith (1977); Mouritsen (2001), S. 47-89, und die weiter unten Anm. 49 zitierten Werke.

48. Vgl. insbesondere Cic. P.red.Sen. 32; P.red.Pop. 13; dom. 54; 110; 129; Pro Sest. 34; In Pis. B11; 23.

49. S. allgemein dazu Lintott (1999), S. 77-83; Vanderbroeck (1987), S. 115; Benner (1987), S. 6470; S. 83-89; S. 108 f.; S. 116-118; Tatum (1999), S. 142-148.

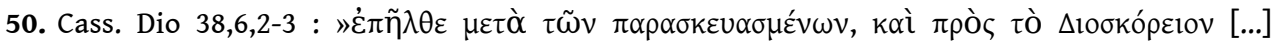

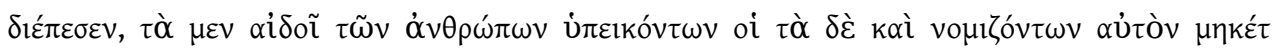

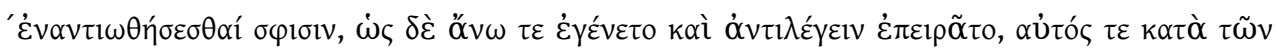

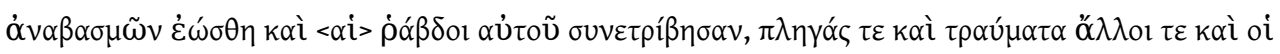

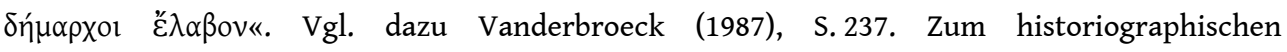
Zusammenhang dieser Berichte zur Abstimmung über dieses Gesetz s. Zecchini (1978).

51. $\mathrm{Zu}$ den zwei Begriffen dieser Alternative, die Cassius Dio nahelegt, ist der Erstere der wahrscheinlichere.

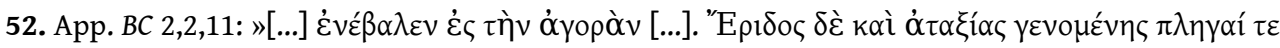

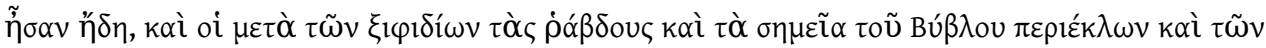

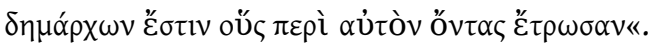

53. Plut. Cat.min. 27-29; vgl. Cic. Pro Sest. 62.

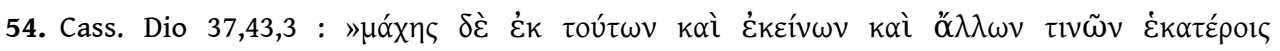

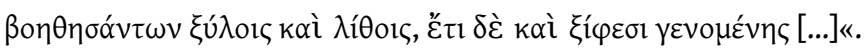

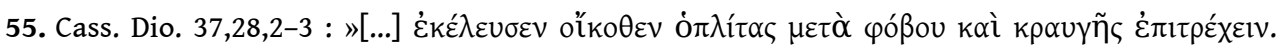

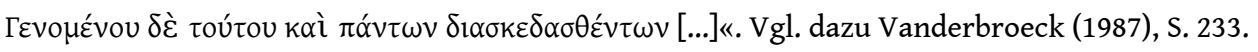

56. Vgl. Cic. Q.fr. 2,3,2: "Dixit Pompeius sive voluit; nam ut surrexit, operae Clodianae clamorem sustulerunt [...] surrexit Clodius. Ei tantus clamor a nostris (placuerat enim referre gratiam) [...]. Ea res acta est [...] cum omnia maledicta, versus denique obscenissimi in Clodium et Clodiam dicerentur. Ille furens et exsanguis interrogabat suos in clamore ipso qui est qui plebem fame necaret. Repondebant operae: >Pompeius`. [...] Factus est a nostris impetus; fuga operarum, eiectus de rostris Clodius, ac nos quoque tum fugimus, ne quid in turba«. Vgl. Cic. fam.1,5a,1; Plut. Pomp. 48,11-12; Cass. Dio 39,18-19, insbesondere 19,1; Vanderbroeck (1987), S. 252 f. Moreau (2003) hat überzeugend gezeigt, dass dieses Vorgehen das Ergebnis einer neueren Entwicklung war; vgl. auch Hiebel (2009), S. $114 \mathrm{f}$, , und zur Politik des Clodius bei der Schaffung eines Publikums Pina Polo (1996), S. 136-140, und Morstein-Marx (2004), S. 133-136.

57. Vgl. Cic. Pro Sest. 75-78.

58. Cic. Pro Sest. 75 : „templo aliquanto ante lucem occupavit«. Vgl. Vanderbroeck (1987), S. 245; Tatum (1999), S. 178.

59. Cic. Pro Sest. 75 : „Cum forum, comitium, curiam, multa de nocte, armatis hominibus ac servis plerisque occupavissent, inpetum faciunt in Fabricium [...]«.

60. Vgl. insbesondere Hopkins (1991), S. 479-498 und besonders S. 492-495; Laser (1997), insbesondere S. 218-225; Flaig (2001), S. 4; Flaig (2003), S. 155-212; Jehne (2003), S. 279-297.

61. Vgl. vor allem die Interpretation, die Sumi (1997), S. 80-102, vorschlägt und die treffend herausstellt, wie die Gewalttätigkeiten, die das Begräbnis des Clodius begleiteten, in den Rahmen eines institutionellen Rituals gehörten. 
INDEX

Schlüsselwörter : römische Republik, Volksversammlung, Institutionen, Gewalt Mots-clés : République romaine, assemblée populaire, institutions, violence

\section{AUTEURS}

JEAN-MICHEL DAVID

Jean-Michel David ist emeritierter Professor für römische Geschichte an der Universität Paris 1 Panthéon-Sorbonne. Nähere Informationen finden Sie hier. 